\title{
Shwachman-Diamond Syndrome
}

National Cancer Institute

\section{Source}

National Cancer Institute. Shwachman-Diamond Syndrome. NCI Thesaurus. Code C61235.

A rare, autosomal recessive disorder characterized by exocrine pancreas insufficiency, skeletal abnormalities, bone marrow dysfunction, and an increased incidence of leukemia. 